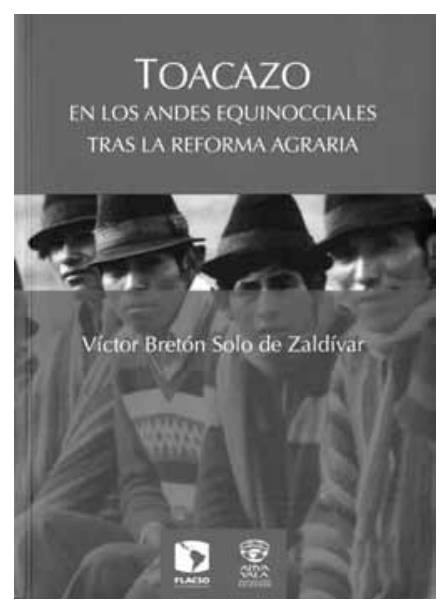

Agrarian Changes in Contemporary Ecuador

Andrés Fábregas Puig

Centro de Investigaciones y Estudios Superiores en Antropología Social-Occidente,

Guadalajara, Jalisco, México apfgup@gmail.com

Desacatos 46 , septiembre-diciembre 2014, pp. 220-222
- Toacazo. En los andes equinocciales

tras la Reforma Agraria

Victor Bretón Solo de Zaldivar, 2012

Facultad Latinoamericana de Ciencias

Sociales-Ecuador, Universitat de Lleida,

Abya-Yala, Universidad Politécnica

Salesiana, Quito, 420 pp.

\section{Cambios agrarios en el Ecuador contemporáneo}

\author{
ANDRÉS FÁBREGAS PUIG
}

A mérica Latina es intensamente rural en una parte considerable de su territorio. No son pocos los países del continente cuyas estructuras agrarias características, originadas en los años de existencia del régimen colonial español o portugués, muestran procesos de transformación. El caso del Ecuador es ilustrativo de estos cambios que implican movimientos de reivindicación étnica, nuevas identidades políticas, configuraciones organizativas producto de las mismas luchas y otros procesos que han desencadenado nuevas trayectorias en los rumbos nacionales de nuestros países. Toacazo es una mirada que desde el observatorio de una parroquia ecuatoriana analiza la transformación del régimen de hacienda y la composición de la etnicidad como un argumento político, eficaz en la movilización y en la articulación de los movimientos populares. Califico al libro como una perspectiva etnohistórica de las transformaciones del agro ecuatoriano, que combina las tradiciones orales con la exploración de las fuentes documentales. Sella esta manera de proceder la etnografía, tejida a la luz de la evidencia, de los testimonios y de la habilidad de observación del antropólogo. Todo integra una lección de método y coloca a la antropología en la tesitura analítica que permite desentrañar los procesos que en los 
momentos actuales están modificando las realidades latinoamericanas. Como dice uno de los apartados del libro: se trata de una monografía local con proyección global. Añado que eso se logra a través del dominio de un campo teórico adecuado y una orientación de método congruente.

El libro de Víctor Bretón está dividido en tres partes precedidas de una presentación y una introducción. En la primera parte se expone la orientación teórica y el contexto, en la segunda se describe el desmoronamiento de la hacienda y en la tercera se analiza la relación entre la organización indígena y las agencias del desarrollo. Un epílogo y las referencias documentales cierran el libro. Las fotos, los cuadros y los mapas son auxiliares que el lector apreciará porque facilitan la lectura y sitúan la narración. Toacazo es un texto que presenta una forma sugerente para emprender una reflexión de largo alcance acerca de los movimientos indígenas en América Latina. Víctor Bretón escogió bien el escenario: la conformación en la sierra ecuatoriana de una de las plataformas étnico-políticas más complejas presentes en la actualidad latinoamericana. Toacazo, una parroquia en los andes equinocciales, es descubierta por la mirada antropológica como un punto de mira para comprender contextos amplios y reconsiderar categorías de análisis que las ciencias sociales han usado y usan. El autor logra describir procesos nuevos porque ha sabido distinguirlos en un "territorio antropológico" que, como el de los Altos de Chiapas, acusa la intensa presencia de la añeja compañía de los antropólogos.

Una lección importante de esta obra es su congruencia. El autor no se aparta de su punto de partida, sino que lo convierte en un eje que vertebra la narración. No resisto la tentación de señalar las cercanías que este texto guarda con la literatura, no sólo por lo bien escrito, sino por la fidelidad a la guía que hace inteligible la lectura. Ese punto de partida, que son los años previos al advenimiento de la primera ley de reforma agraria en Ecuador, le permite a Bretón reconstruir la naturaleza y las características de la estructura agraria de Toacazo hacia 1960 y desde ahí seguir dicha reforma como un entramado de relaciones políticas, actitudes culturales y nudos de relaciones sociales hasta establecer un panorama de formación de un Estado nacional, en cuyo proceso el pasado es parte del presente. Pericia, sin duda bien desplegada, es lo que encontramos. Porque en este proceder existe un reto: deconstruir el metadiscurso del Estado nacional, hacerlo inteligible y con ello situar — que no es poca cosa- el paso de una identidad étnica a una fuerza de movilización política. Víctor Bretón cumple con el propósito de mirar al mundo desde su observatorio local.

Me parece que este libro encierra sugerencias para los interesados en explicar los nuevos tiempos en Chiapas desde la perspectiva de las transformaciones del ámbito rural. Lo digo porque Víctor Bretón identifica procesos que tienen relación con la etnificación del desarrollo rural, lo que en México y en Chiapas nos retrotrae a las discusiones planteadas por Guillermo Bonfil Batalla a través del concepto de “etnodesarrollo" y del "México profundo". Es decir, el examen de cómo se transita de la lucha por la tierra al "nosotros en desarrollo" desde el punto de vista indígena. A partir de este mirador descubrimos las falacias de categorías que aparentan señalar líneas de decisión propia para descubrir los dogmas neoliberales. La superación de estos dogmas incluye la reflexión crítica incluso acerca de la noción del "buen vivir" empleada por los propios pueblos indígenas. Leo en el argumento de Víctor Bretón un factor de gran significado: Toacazo muestra que es el mundo de la hacienda el que enmarca la politización de la etnicidad y no los planteamientos del neoliberalismo sobre la democracia y la igualdad ante la ley. La hacienda es un universo de dominación en el que emerge la identidad étnica y la capacidad de transformarla en movilización política, en factor de crítica de la condición del dominado. Me parece encontrar aquí una sugerencia, que destaco: las propias formas 
de dominación generan las estrategias de movilización popular. Es un argumento que nos lleva hacia caminos complejos en el debate, que implica pensar en el papel de las ideologías, las doctrinas políticas, los discursos alusivos a la libertad y los caminos por los que se moviliza la gente.

En Ecuador y en comparación con los procesos en México, esa transfiguración de la hacienda es un suceso de nuestros días. En México, las grandes transformaciones de las haciendas se remontan al siglo XIX y, por supuesto, a la Revolución Mexicana en los inicios del siglo xx. En Ecuador, estos cambios siguieron ritmos distintos, algunos de ellos desde el siglo XIX, sin que hubiera un movimiento político equiparable a la Revolución. Todavía en la década de 1960 los gamonales y las añejas estructuras de la dominación colonial estaban presentes en el país andino. Será hasta 1964 que se aplique la reforma agraria en el Ecuador. Y las estructuras no cayeron de la noche a la mañana.

La disolución de las haciendas no siguió un camino único. Víctor Bretón narra, discute y explica cómo funcionaron los diferentes modelos de transformación de las haciendas ecuatorianas e incluye las que pertenecían a la mismísima Universidad Central del Ecuador. El relato de cómo esta gran universidad se convirtió en terrateniente y cómo dejó de serlo es una de las partes más atractivas del libro y una lección de que ningún surrealismo supera al de América Latina y el Caribe. También es importante el sacar a flote las viejas estructuras de dominación establecidas en los tiempos coloniales, y por supuesto la longevidad y tenacidad de las relaciones clientelares, que recorren las formas y las estructuras organizacionales en América Latina y el Caribe. Hasta en los santos patrones están presentes los viejos señores de la tierra, los dominadores. Ecuador no es la excepción en las prolongaciones del hecho colonial. Percibir este factor permite a Víctor Bretón trazar un proyecto crítico, una antropología basada en ese proyecto y evitar la idealización de los procesos. La habilidad del autor facilita terminar el libro con lo que inició y conducir al lector hacia las bases analíticas que operaron en todo su desarrollo, lo que muestra su eficacia para desvelar los procesos y al final presentar a los protagonistas: la gente de Ecuador.

En las páginas de Toacazo están presentes las anticuadas estructuras de ese mundo andino - ¿se puede hablar de un mundo tal? - que fue resultado de la situación colonial, de líderes y organizaciones construidas a través de un tiempo que va y viene entre las exigencias del presente y las ataduras del pasado, de un Estado nacional que lejos de debilitarse se ha reconfigurado y fortalecido y se erige como una suerte de nuevo patrón articulador del clientelismo. En el medio de todo ello los movimientos indígenas de Ecuador muestran signos propios y enseñan las transformaciones de la etnicidad al calor de las batallas políticas. Más fascinante no podía ser.

Termino este breve comentario con una pregunta que se hace explícita casi al final de la obra, pero que está entretejida en toda su extensión: ¿están América Latina y el Caribe ante un cambio de época? Hablamos de época, no de cambios en las solas relaciones de producción o en las formas políticas. ¿Estamos ante un nuevo tiempo? Allí quedan las preguntas que Toacazo nos alienta a reflexionar. Es probable que no las respondamos, pero en el camino es factible escribir más Toacazos y ofertar a nuestras sociedades un abanico comparativo de sus propias realidades y de los destinos delineados en las entrañas profundas de sus historias. Una palabra final: Víctor Bretón ha escrito con pasión, una doble pasión, la que siente por el Ecuador y la que mantiene por la antropología. He notado esas pasiones a lo largo del libro. Allí está el trabajo de campo, el gusto por los paisajes, el dominio de las categorías analíticas, la gente de carne y hueso, y las historias profundas que enlazan al antropólogo con el mundo. D 